\title{
LACTATE DEHYDROGENASE ISOENZYMES AND THE REPRODUCTIVE CYCLE IN THE RAT
}

\author{
CARLA PATTERSON AND C. J. MASTERS \\ Department of Biochemistry, University of Queensland, \\ St Lucia, Qld 4067, Australia
}

(Received 9th August 1971, accepted 23rd November 1971)

\begin{abstract}
Summary. Changes in the properties and distribution of LDH isoenzymes have been studied in the tissues and fluids of the reproductive tract during the oestrous cycle and during postnatal development in the rat. The specific activity values of the tissue LDH over this period indicate a sequential response along the length of the tract. In the extracellular secretions of the tract, peak activities coincide with, or closely follow, peak values in adjacent tissues and isoenzyme patterns tend to bear a reciprocal relationship between individual sections of the tract tissues and the enclosed secretions. The high levels of extracellular activity occurring within the oviducal secretion appear to be the result of contributions from the circumjacent tissues along the length of the tract, the Fallopian tube being indicated as an especially rich source. Hormonal and developmental influences on the synthesis of LDH isoenzymes are discussed in relation to the changes observed.
\end{abstract}

\section{INTRODUCTION}

Lactate dehydrogenase ( $\mathrm{LDH}$ ) exists in most mammalian tissues in five molecular forms of sub-unit composition $\mathrm{A}_{4}$ (LDH-5), $\mathrm{A}_{3} \mathrm{~B}$ (LDH-4), $\mathrm{A}_{2} \mathrm{~B}_{2}$ (LDH-3), $\mathrm{AB}_{3}(\mathrm{LDH}-2)$ and $\mathrm{B}_{\mathbf{4}}(\mathrm{LDH}-1)$, respectively; $\mathrm{A}$ and $\mathrm{B}$ being different sub-units under the control of separate genetic loci (Cahn, Kaplan, Levine \& Zwilling, 1962; Wieland \& Pfleiderer, 1963; Markert, 1963). During vertebrate development, progressions of these multiple forms of LDH are demonstrable in many tissues, and have contributed to an understanding of differential gene control at this time and to the metabolic characteristics of individual tissues (Fieldhouse \& Masters, 1966; Hinks \& Masters, 1966).

As the reactants of this enzyme are especially important as energy sources during early growth and cell multiplication of the mammalian embryo (Brinster, 1967; Gibson \& Masters, 1970a), and as both preimplantation ova and oviducal fluid appear to be associated with high levels of the enzyme (Gibson $\&$ Masters, 1970b), it was considered to be of value to define the nature of this enzyme in all the major sections of the female reproductive tract, and to establish the type of changes incurred during the normal oestrous cycle.

This communication presents detailed information on the changes in the pattern of $\mathrm{LDH}$ in the tissues and fluids of the reproductive tract during the oestrous cycle in the rat. These data, beside being of intrinsic biological in- 
interest, were a necessary prerequisite to further investigations of hormonal influences on specific proteins in the reproductive process. Previous studies by other workers, published during the preparation of this manuscript, have briefly described similar data in regard to the uterus alone (Galbraith, Robb \& Heald, 1970) but, in the present context, far more extensive information was considered necessary.

\section{MATERIALS AND METHODS}

Mature female rats (approximate body weight $180 \mathrm{~g}$ ) of the locally bred Wistar strain were separated into groups according to the stage of the oestrous cycle. This was determined by taking vaginal smears which were stained with methylene blue, and the cell types were then examined microscopically (Velardo, 1958). The reproductive tracts were excised from at least six rats at each stage of the cycle and were separated anatomically as follows: ovary, Fallopian tube, proximal and distal uterine horns and corpus uteri. Fluid was collected from the Fallopian tubes and component parts of the uterus by flushing twice with minimal quantities of $0.01 \mathrm{~m}$-tris-HCl buffer, $\mathrm{pH} 8.0$. The tissues were separately homogenized in a glass tube with a Teflon pestle so as to produce a final content of $30 \%(\mathrm{w} / \mathrm{v})$ tissue in the above buffer. Both homogenates and fluids were then centrifuged at $50,000 \mathrm{~g}$ at $5^{\circ} \mathrm{C}$ for $1 \mathrm{hr}$. The reproductive tracts from rats of various pre-mature ages were also excised and treated in a similar manner.

The activity of $\mathbf{L D H}$ was determined by measuring the rate of optical density decrease at $340 \mathrm{~m} \mu$ resulting from the oxidation of NADH in the presence of pyruvate as substrate and an appropriate quantity of enzyme at $30^{\circ} \mathrm{C}$ (Wroblewski \& La Due, 1955). Protein was determined by the method of Lowry, Rosebrough, Farr \& Randall (1951) with recrystallized bovine serum albumin as a standard. Electrophoretic patterns of isoenzyme distribution were established by running vertical starch gels with a tris-glycine buffer system $(0.03 \mathrm{M}, \mathrm{pH} \mathrm{9.0)}$. Regions of LDH activity were detected with a tetrazolium dye stain. Gels were then scanned on an integrating densitometer in order to calculate the intensity of the bands of activity, and the relative contribution of A- and B-type LDH activity (Hinks \& Masters, 1964; Holmes \& Masters, 1967; Georgiev, Holmes \& Masters, 1970).

\section{RESULTS}

The specific activities of $\mathrm{LDH}$, and the percentage of A-type contribution of this enzyme activity, for the tissues and fluids examined at pro-oestrus, oestrus, metoestrus and dioestrus are summarized in Tables 1 and 2, respectively. The sources of highest activity in the tract tissues at most stages of the cycle were the ovary and Fallopian tube. In both these tissues, the specific activity reached a peak at pro-oestrus and declined to the 'oestrus' stage. In the ovary, it continued to decline until metoestrus, and then rose quite sharply to the dioestrous level. The Fallopian tube, on the other hand, showed a small rise at metoestrus, then declined sharply to dioestrus. Fluctuations of activity were not 
as pronounced in the uterus, but it was evident that the pattern of change varied in the different segments. Minimal activity occurred during metoestrus in the proximal uterine horn, during dioestrus in the distal uterine horn, and at oestrus in the corpus uteri: peak values also followed a progression: during pro-oestrus in the proximal uterine horn, at oestrus in the distal portion of the horn, and during dioestrus in the uterus.

The LDH activity in the Fallopian tube fluid was similar to that in the tract tissues, reaching a peak at pro-oestrus, and then rapidly declining until a

TABLE 1

SPECIFIC ACTIVITIES OF LDH IN THE TISSUES AND FLUIDS OF THE RAT REPRODUGTIVE TRAGT AT VARIOUS STAGES DURING THE OESTROUS CYGLE

\begin{tabular}{|c|c|c|c|c|}
\hline Tissue & Pro-oestrus & Oestrus & Metoestrus & Dioestrus \\
\hline $\begin{array}{l}\text { Ovary } \\
\text { 'Fallopian tube } \\
\text { 'Proximal' uterine horn } \\
\text { 'Distal' uterine horn } \\
\text { Corpus uteri } \\
\text { Fallopian tube fluid } \\
\text { 'Proximal' }\end{array}$ & $\begin{array}{l}1.8 \pm 0.3 \\
1.8 \pm 0.2 \\
1.2 \pm 0.2 \\
1.1 \pm 0.2 \\
0.8 \pm 0.1 \\
2.4 \pm 0.3\end{array}$ & $\begin{array}{l}1.2 \pm 0.2 \\
1.5 \pm 0.2 \\
1 \cdot 1 \pm 0.1 \\
1 \cdot 2 \pm 0.2 \\
0.9 \pm 0.1 \\
1 \cdot 1 \pm 0.2\end{array}$ & $\begin{array}{l}1 \cdot 0 \pm 0.1 \\
1.6 \pm 0.2 \\
0.9 \pm 0.1 \\
0.9 \pm 0 \cdot 1 \\
0.9 \pm 0 \cdot 1 \\
1 \cdot 0 \pm 0.2\end{array}$ & $\begin{array}{l}1 \cdot 7 \pm 0 \cdot 2 \\
0 \cdot 8 \pm 0 \cdot 1 \\
1 \cdot 2 \pm 0 \cdot 2 \\
0 \cdot 5 \pm 0 \cdot 1 \\
1 \cdot 3 \pm 0 \cdot 2 \\
1 \cdot 4 \pm 0 \cdot 2\end{array}$ \\
\hline $\begin{array}{l}\text { uterine horn fluid } \\
\text { Fluid of corpus uteri }\end{array}$ & $\begin{array}{l}1 \cdot 1 \pm 0.2 \\
0.4 \pm 0 \cdot 1\end{array}$ & $\begin{array}{l}1.5 \pm 0.2 \\
0.5 \pm 0.1\end{array}$ & $\begin{array}{l}0.5 \pm 0.1 \\
0.6 \pm 0.1\end{array}$ & $\begin{array}{l}0.9 \pm 0.2 \\
0.7 \pm 0.1\end{array}$ \\
\hline
\end{tabular}

Results are expressed as specific activities in i.u./mg protein and represent the means of six experimental values $( \pm$ S.E. $)$

TABLE 2

PERGENTAGE A-TYPE LDH OF THE TISSUES AND FLUIDS OF THE RAT REPRODUGTIVE TRACT AT VARIOUS STAGES DURING THE OESTROUS GYGLE

\begin{tabular}{l|c|c|c|c}
\hline \multicolumn{1}{c|}{ Tissue } & Pro-oestrus & Oestrus & Metoestrus & Dioestrus \\
\cline { 2 - 2 } & $66 \pm 2$ & $60 \pm 2$ & $82 \pm 3$ & $70 \pm 3$ \\
Ovary & $87 \pm 3$ & $84 \pm 3$ & $75 \pm 1$ & $77 \pm 2$ \\
'Fallopian tube & $78 \pm 3$ & $84 \pm 2$ & $85 \pm 3$ & $77 \pm 2$ \\
'Proximal' uterine horn & $86 \pm 3$ & $77 \pm 3$ & $76 \pm 2$ & $88 \pm 3$ \\
'Distal' uterine horn & $73 \pm 3$ & $61 \pm 2$ & $73 \pm 3$ & $70 \pm 2$ \\
Corpus uteri & $83 \pm 3$ & $87 \pm 2$ & $88 \pm 3$ & $94 \pm 3$ \\
Fallopian tube fluid & $92 \pm 3$ & $91 \pm 2$ & $88 \pm 3$ & $94 \pm 3$ \\
'Proximal' and 'distal' & uterine horn fluid & $90 \pm 3$ & $95 \pm 2$ & $85 \pm 3$ \\
Fluid of corpus uteri & $92 \pm 2$ & $80 \pm 3$ & \\
\hline
\end{tabular}

Results are expressed as the means of six experimental values ( \pm S.E.).

recovery was evident at dioestrus. The pattern of activity of fluid from the uterine horn reached a minimum at metoestrus and a maximum at prooestrus and, with the fluid from the corpus uteri, minimal specific activity occurred during pro-oestrus.

From Table 2, it is evident that the ovary showed quite a marked transient increase in the percentage of A-type activity at metoestrus, whereas the Fallopian tube appeared to exhibit a slight decrease at the corresponding stage with the greatest percentage of A-type contribution occurring at pro-oestrus. The 
minimum of A-type contribution occurred at dioestrus in the proximal uterine horn and at metoestrus in the distal uterine horn; in the corpus uteri, the minimum value occurred at oestrus. Both the Fallopian tube and uterine fluids showed maximal A-type contribution at oestrus, whereas the fluid from the corpus uteri showed two peaks, at pro-oestrus and metoestrus.

The specific activities of LDH and percentage A-type sub-units in the reproductive tracts of young rats are illustrated in Text-fig. 1. In the ovary, specific activities increased in a regular manner during this period of maturation but, in the region of the uterus and Fallopian tube, the increase in specific activity was

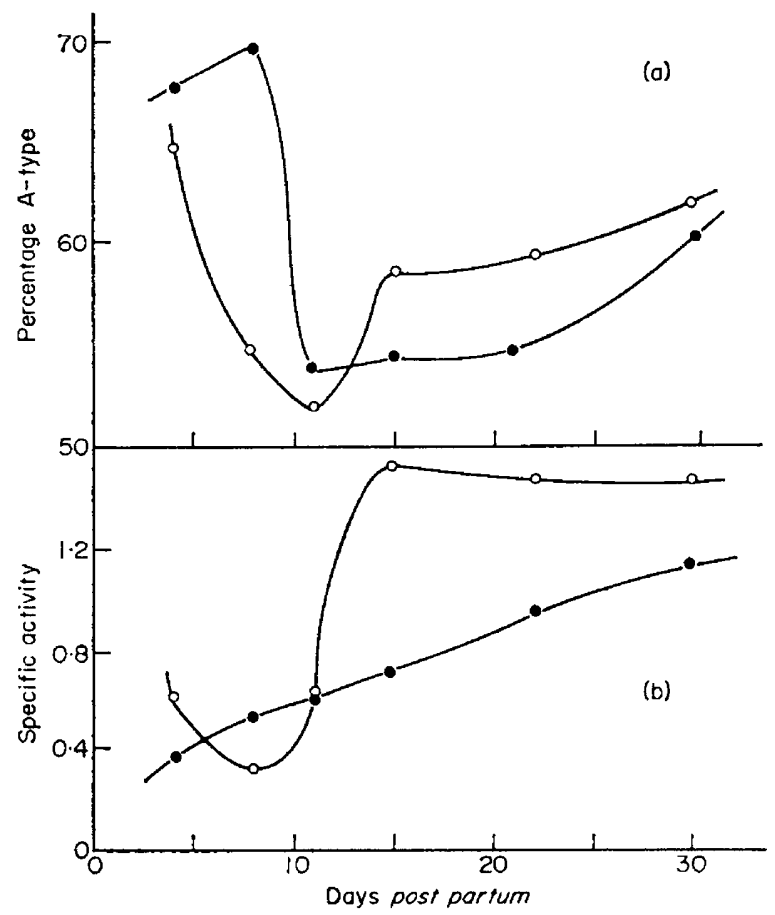

TExT-FIG. 1. (a) Percentage of A-type LDH activity in the tissues of the reproductive tract in pre-mature rats from 4 to 30 days post partum. (b) Specific activity of $\mathrm{LDH}$ in the tissues of the reproductive tract in pre-mature rats. 1 , Ovary; 0 , remainder of reproductive tract.

quite sharp between 8 and 15 days, then stabilized at levels approximating to those in the adult.

The early developmental stages also encompassed marked changes in the sub-unit type of LDH in the reproductive tract. In the ovary, for example, a considerable shift towards decreased A-type contribution occurred between 8 and 11 days, after which a more gradual increase in A-type content towards A-type levels was evident. In the remainder of the tract (which was, in general, sampled as a whole because of the small size), percentage A-type values again fell between 5 and 11 days, rose quite sharply at 15 days, then moved slowly towards adult levels. Samples of fluid secretions within the uterine and Fallo- 
pian tubes exhibited an even more marked shift towards increased A-type content in the period between 11 and 20 days after birth.

The isoenzyme patterns for lactate dehydrogenase are illustrated in Text-fig. 2 with a presentation of the zymograms for the components of the rat reproductive tract in dioestrus.

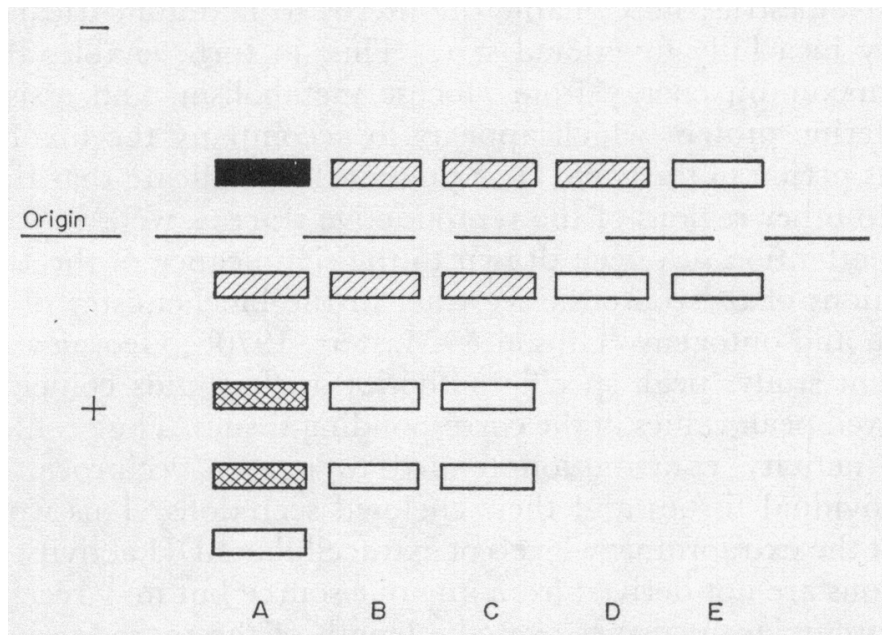

TEXT-FIG. 2. Zymogram of LDH in tissue and fluids from the rat reproductive tract at dioestrus. A, ovary; B, Fallopian tube; C, uterine horn; D, uterine horn fluid; E, fluid of corpus uteri.

\section{DISGUSSION}

The alterations in the specific activities and relative expressions of A- and B-type $\mathrm{LDH}$ observed in the corpus uteri during the present investigations are in overall agreement with the patterns of response observed recently for both the rat and human uterus (Galbraith et al., 1970; Fottrell, Spellman \& O'Dwyer, 1969). In connection with the timing of these changes, and in particular with the occurrence of a high A-type contribution in pro-oestrus, it seems relevant to comment on the correlation between the increase of A-type activity and the pattern of circulating oestrogen (Velardo, 1958), and to note that previous studies have indicated that oestradiol exerts a directional influence on LDH synthesis in the rat and rabbit uterus, preferentially increasing the production of A-type sub-units (Goodfriend \& Kaplan, 1964; Wilson, 1969).

In addition to the data for the uterus, the present results allow a considerable extension of the previously available information in regard to the overall properties of lactate dehydrogenase during the oestrous cycle. In viewing the specific activity response of the reproductive tract as a whole, it is evident that the component parts do not act in synchrony; rather, a sequential response is indicated. For example, minimal activities of $\mathrm{LDH}$ occur at metoestrus in the ovary, dioestrus in the Fallopian tube and distal uterine horn, and pro-oestrus/ oestrus in the corpus uteri (Table 1). This emphasizes the need for careful delineation of the region of the tract studied during assessment of the timing of 
hormone enzyme interrelationships. Again, pro-oestrus (the time of maximal oestrogen secretion) coincides with a high content of A-type activity, not only in the corpus uteri, but also in the uterine horns, Fallopian tube and ovary. The indications are that in this respect all these portions of the reproductive tract respond to oestradiol in a parallel manner. Galbraith et al. (1970) have suggested that the decrease in the proportion of A-type sub-units, which is noticeable at dioestrus, may enable the uterus to maintain tricarboxylic acid cycle activity in a fully functional state. This, in turn, enables the uterus to derive the maximum energy from glucose metabolism, and assists the catabolism of uterine protein which appears to accompany the involution of the uterus at this period of the cycle. The present data indicate that this reasoning may apply to other regions of the reproductive tract as well.

Recently, attention has been drawn to the significance of the LDH activity in the secretions of the reproductive tract in the biochemistry of mammalian reproduction and ontogeny (Gibson \& Masters, 1970b; Georgiev et al., 1970). In the present study, peak specific activities in the fluids coincided with, or closely followed peak values in the corresponding tissues. The profiles of sequential A-type activity contribution tended to bear a reciprocal relationship between individual tissues and their enclosed secretions. This would seem to indicate that the extraordinary levels of extracellular LDH activity occurring in these secretions are not derived from any one source but may receive contributions from circumjacent tissues over the length of the reproductive tract. The Fallopian tube, however, appears to be the major site of variation. This particular localization affords good correlation with histochemical studies of the cyclic process, and with studies of the influence of other reproductive hormones on the $\mathrm{LDH}$ isoenzymes of the rat and rabbit reproductive tract (Gibson \& Masters, 1970b; Georgiev et al., 1970; C. J. Masters, unpublished).

The ontogeny of the reproductive tract is associated with quite marked changes in the isoenzyme distribution of these tissues in the infant animal (notably between the ages of 8 and 15 days post partum), and these variations are especially noticeable in the oviducal tissues and fluids. While the early embryonic patterns of LDH isoenzymes are species specific (Fieldhouse \& Masters, 1966; Hinks \& Masters, 1966), the enzyme is comprised almost entirely of A-type activity in the rat before functional differentiation (Fine, Kaplan \& Kuftinec, 1963), and at subsequent early maturation stages most tissues in this animal show an increase in B-type contribution with development. This directional shift is consistent with the tissue patterns observed in the earliest specimens studied in the present investigation (Text-fig. 1). Since the female reproductive tract is functional only at or near maturity, the subsequent incremental alteration of A-type LDH activity in the juvenile rat would seem to be indicative of a specialized maturation process in preparation for its characteristic rôle in adult life.

\section{ACKNOWLEDGMENT}

These investigations were supported in part by grants from the Australian Research Grants Committee. 


\section{REFERENCES}

BRINSTER, R. L. (1967) Lactic dehydrogenase activity in preimplantation rat embryo. Nature, Lond. 214 1246.

Cahn, R., Kaplan, N. O., Levine, L. \& Zwilling, E. (1962) Nature and development of lactic dehydrogenase. Science, N.Y. 136, 962.

Fieldhouse, B. \& MASTERs, C. J. (1966) Developmental redistributions of porcine lactate dehydrogenase. Biochim. biophys. Acta, 118, 538.

Fine, I. H., Kaplan, N. O. \& Kuftinec, D. (1963) Developmental changes of mammalian lactic dehydrogenase. Biochemistry, 2, 116.

Fottrell, P. F., Spellman, C. M. \& O'Dwyer, E. (1969) Lactate dehydrogenase isoenzymes in human endometrium. Clinica chim. Acta, 26, 391.

Galbratth, H., Robe, D. A. \& Heald, P.J. (1970) Changes in the proportion of ' $H$ ' and 'M' subunits of lactate dehydrogenase in rat uterus during an oestrus cycle. Biochim. biophys. Acta, 201, 391.

Georgiev, P., Holmes, R. S. \& Masters, C. J. (1970) Extracellular lactate dehydrogenase-hormonal influences on the oviducal isoenzymes. Biochim. biophys. Acta, 222, 155.

Gibson, C. \& MASTERs, C. J. (1970a) On the lactate dehydrogenase of preimplantation mouse ova. FEBS Letters, 7, 277.

Gibson, C. \& MAstzRs, C. J. (1970b) Oviducal lactate dehydrogenase. F. Reprod. Fert. 22, 157.

Goodfriend, T. L. \& KAPLAN, N. O. (1964) Effects of hormone administration on lactic dehydrogenase. F. biol. Chem. 239, 130.

Hinks, M. \& MastrRs, C. J. (1964) Developmental changes in ruminant lactate dehydrogenase. Biochemistry, 3, 1789.

Hinks, M. \& Masters, C. J. (1966) The ontogenetic variformity of lactate dehydrogenase in feline and cavian tissues. Biochim. biophys. Acta, 130, 458.

Holmes, R. S. \& MAsters, C. J. (1967) The developmental multiplicity and isoenzyme status of cavian esterases. Biochim. biophys. Acta, 132, 379.

Lowry, O. H., Rosebrovgh, N. J., FARR, A. K. \& Randall, R. J. (1951) Protein measurement with the folin phenol reagent. F. biol. Chem. 193, 265.

MARKERT, C. L. (1963) Epigenetic control of specific protein synthesis in differentiating cells in cytodifferentiation and micromolecular synthesis, pp. 65-84. Academic Press, New York.

Velardo, J. T. (1958) The anatomy and endocrine physiology of the female reproductive system. In: The Endocrinology of Reproduction. Oxford University Press, New York.

Wieland, T. \& Pfleiderer, G. (1963) Multiple Formen von Enzymen. In: Advances in Enzymology, Vol. 25, p. 329. Ed. F. F. Nord. Interscience, New York.

Wruson, E. W. (1969) The effect of oestradiol-17 $\beta$ on enzymes concerned with metabolism of carbohydrate in human endometrium in vitro. $\mathcal{7}$. Endocr. 44, 63.

WrobleWski, F. \& LA DUE, J. S. (1955) Lactic dehydrogenase activity in blood. Proc. Soc. exp. Biol. Med. $90,210$. 